\title{
VARIATION IN THE PHYSICO-MECHANICAL PROPERTIES OF GRANITIC AGGREGATES IN OGUN STATE, NIGERIA
}

\author{
S. S. Omopariola ${ }^{1, *}$ and A. A. Jimoh ${ }^{2}$ \\ 1, Civil Engineering Department, The Federal Polytechnic Ilaro, Ilaro, OGun STATE, NiGERIA \\ 2, Civil ENGINEERING DEPARTMENT, UNIVERSITY OF ILORIN, ILORIN, KWARA STATE, NIGERIA \\ E-mail addresses:1 hfeforchrist@yahoo.com, 2aajimoh4real@yahoo.com
}

\begin{abstract}
Coarse aggregate is an essential constituent of concrete constituting about $60 \%$ to $80 \%$ of concrete depending on the mix ratio. Granite is reported to be the most widely distributed plutonic rock in the earth crust. It is predominantly available in various parts of Ogun State of Nigeria. Its different properties have been known to strongly influence the fresh and hardened state properties of concrete. In this study, samples of four different sizes of granites (9.5mm, $12.5 \mathrm{~mm}, 19 \mathrm{~mm}$ and $25 \mathrm{~mm}$ ) were obtained from four different quarry sites across the state. The Physical properties such as specific gravity, moisture content and water absorption and the Mechanical properties such as aggregate impact value and aggregate crushing value of the samples were evaluated. The results of the specific gravity, moisture content and water absorption vary from 2.61 to $2.86,0.69$ to $1.22 \%, 0.16$ to $2.13 \%$ respectively. While the aggregate impact value and aggregate crushing value vary from 18.30 to $28.12 \%$ and 6.21 to $9.45 \%$ respectively. It was therefore concluded that there are variations in the physical and mechanical properties of granites produced in Ogun State of Nigeria. The observed variations occur in relation to the various sizes and for the different quarry sites.
\end{abstract}

Keywords: Variation, Physical Properties, Mechanical Properties, Granite.

\section{INTRODUCTION}

The use of Granite in the building construction industry is fast replacing the use of washed and unwashed gravel in Nigeria. In the opinion of [1], a wide range of granitic rock is present in masonry constructions, depending on their petrographic features, such as grain size and internal texture. This according to [2] necessitates the characterization of granites so as to be able to provide important input data for the design of the structures founded on or in the rock. Granite is the most widely distributed plutonic rock in the earth crust. Granitic rocks are defined as the intrusive igneous rocks that are widely used in the construction industries as dimension stone, aggregates etc. due to their high strength, abrasion resistance and durability $[3,4]$.

Observation by [3] indicated that there is a considerable variation in the physical properties like specific gravity, water absorption, dry and saturated densities and Unconfined Compressive Strengths of the rock samples of different locations. According to [5] the observed variations in the measured physical properties of rocks are due to the anisotropic nature of the rocks. These variations can occur in rocks within the same locality, but few distances apart. Thus, similar or the same rock type within the same locality may not be suitable for the same geologic and engineering purpose. In the opinion of [6], slight variation in this parameter can lead to significant variation in UCS which can cause serious disruption of engineering designs.

It was also stated by [6] that the physical and engineering properties of such rocks are known to be affected by many factors. These variations in the physical and strength properties of rock according to [6] depend upon many factors which include geological, lithological, physical, mechanical and environmental factors. Research findings by [2] indicated that the physical properties like specific gravity, water absorption and densities of rock samples collected from different locations vary considerably. Rocks exhibit a vast range of physical and mechanical properties which reflect vast varieties of structures fabric and compound, some basic properties measurements which are essential for describing rocks [7]. It therefore pre supposes that the physical and mechanical properties of granites will also exhibit a wide range of variation 
from location to location.

The study is therefore aimed at verifying this supposition. To this end laboratory tests were carried out to determine the physical and mechanical properties of various sizes of aggregates produced in different parts of Ogun State in Nigeria. Subsequently, the coefficient of variation was determined by analysis using SPSS statistical software.

\section{MATERIALS AND METHODS}

\subsection{Procurement of Materials}

Procurement of granites were made from four different quarry sites located at Omoologede along Abeokuta Igboora road and Papa Adeosun along Abeokuta Ibadan road in Abeokuta North Local Government Area and Odeda Local Government Area respectively. The other two locations are at Ishara in Remo North Local Government Area and Ago - Iwoye in Ijebu North Local Government Area. All the quarry sites are in Ogun State of Nigeria.

\subsection{Laboratory Tests on Materials}

Laboratory tests were carried out on the Physical properties viz - a viz the specific gravity, water absorption and moisture content in accordance with [8, 9] respectively. While the tests carried out on the
Mechanical properties are Aggregate Impact and Crushing Value.

\subsection{Test on Specific Gravity and Water Absorption of Aggregate}

The specific gravity and absorption were calculated using equations 1 and 2 respectively.

$$
\begin{aligned}
S G & =\frac{A}{B-C} \\
A B & =\frac{B-A}{A} \times 100 \%
\end{aligned}
$$

Where SG is the bulk specific gravity, $A B$ is percentage of absorption (\%), A is weight of oven-dry sample in air (g), B is weight of SSD sample in air (g) and C is the weight of SSD sample in water.

\subsection{Test on Moisture Content of Aggregate}

The moisture content was evaluated using equation 3

$$
M C=\frac{M_{2}-M_{3}}{M_{2}-M_{1}} \quad \times 100
$$

Where MC is Moisture Content (\% dry mass), M1 = weight of empty container, M2 = weight of container + sample and M3 = weight of container + oven dry sample, $M_{1}$ is $M 2$ is and $M 3$. The result is reported to the nearest $0.1 \%$ of the dry weight.

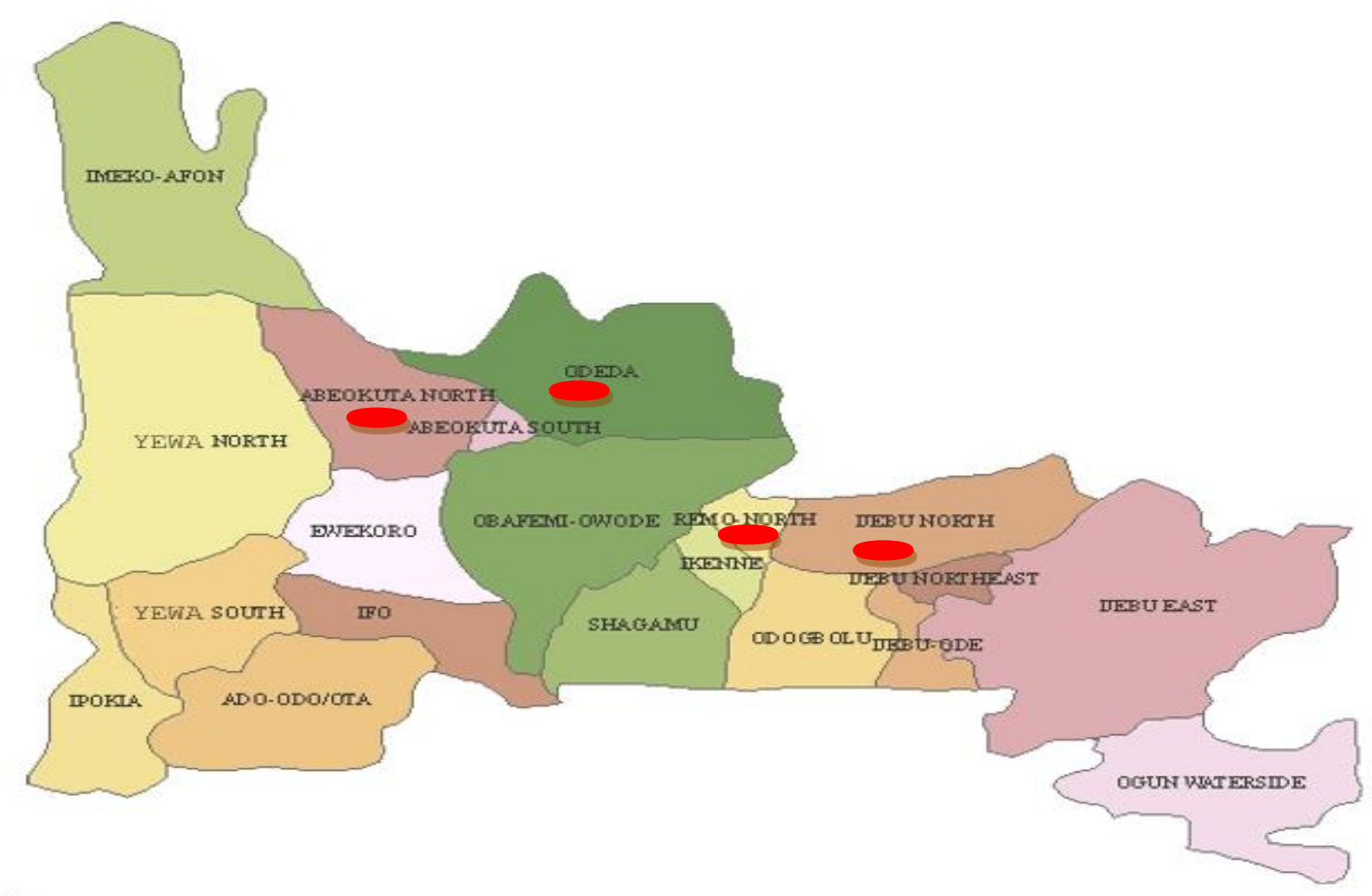

Figure 1: Map of Ogun State showing the location of collection of granite aggregate samples Location of collection of samples 


\subsection{Test on Aggregate Impact Value and Aggregate Crushing Value Specific Gravity of Aggregate}

The Aggregate Impact Value (AIV) and Aggregate Crushing Value (ACV) were the mechanical properties determined by laboratory experiment in accordance with the specifications in BS 812: Part 112: 1990 and BS 812 Part 110: 1990 respectively. The results of AIV and ACV was evaluated using equation 4.

$$
P=\frac{B \times 100}{A}
$$

Where $\mathrm{P}$ is Percentage fines $\mathrm{A}$ is the mass of surface-dry sample $(\mathrm{g})$ and $\mathrm{B}$ is the mass of the fraction passing the $2.36 \mathrm{~mm}$ sieve $(\mathrm{g})$.

\subsection{Analysis of Test Results}

Test results were analysed using SPSS software. The software was used to determine the standard deviation, mean, and variance of test results. The coefficient of variation was determined by dividing the value of the standard deviation by the mean value.

$$
C_{V}=\frac{\sigma}{x}
$$

Where $\mathrm{Cv}$ is the coefficient of variation, $\sigma$ is the standard deviation of test results and $\mathrm{x}$ is the mean value of test results.

\section{RESULTS AND DISCUSSIONS.}

\subsection{Variation in Values of Specific Gravity}

Results of standard deviation, mean, coefficient of variation and variance is presented in Table 1 . From Table 1, it was observed that $25 \mathrm{~mm}$ granites had the highest value of coefficient of variation of 11.87 while $12.5 \mathrm{~mm}$ had the least value of $0.88 .19 \mathrm{~mm}$ granite size had the highest value of variance of 0.013 , while both the $12,5 \mathrm{~mm}$ and $25 \mathrm{~mm}$ granites had the least values of 0.001 . It therefore implies that $12.5 \mathrm{~mm}$ granites with the least coefficient of variation had smaller residuals relative to the predicted value and $25 \mathrm{~mm}$ with higher

Coefficient of variation had the greater dispersion in the variable. However, all the various sizes had low values of coefficient of variation thus suggestive of a good model fit. The analysis of variation of granite samples on the basis of the source that is location of quarry sites as presented in Table 2, indicates that samples from all the sites had low coefficient of variation. The sample from Ago Iwoye had the highest value of 3.73 and that of Omoologede had the least value of 1.05. Granite sample from Ago Iwoye also had the highest value of variance of (0.011) while sample from both Omoologede and Papa Adeosun had the least value of 0.001 .
In all, the values of the specific gravity for all the granite sizes and sites fall within the range if values of 2.4 to 2.9 stipulated in literatures and relevant codes [12 15].

\subsection{Variation in Values of Water Absorption}

Results of standard deviation, mean, coefficient of variation and variance of the water absorption for the various sizes and for the different quarry sites are presented in Table 3 and 4 . The observations on the results are discussed below.

Table 1 Statistical Analysis for Specific Gravity of Aggregates for all the Granite Sizes

\begin{tabular}{lllll}
\hline Aggregate size & $\Sigma$ & $\mathrm{X}$ & $\mathrm{C}_{\mathrm{v}}$ & Variance \\
\hline $9.5 \mathrm{~mm}$ & 0.0709 & 2.728 & 2.6 & 0.005 \\
$12.5 \mathrm{~mm}$ & 0.0238 & 2.695 & 0.88 & 0.001 \\
$19 \mathrm{~mm}$ & 0.1139 & 2.715 & 4.19 & 0.013 \\
$25 \mathrm{~mm}$ & 0.3055 & 2.707 & 11.87 & 0.001 \\
\hline
\end{tabular}

Table 2: Statistical Analysis for Specific Gravity of Aggregates for all the Quarry Sites

\begin{tabular}{lllll}
\hline Aggregate size & $\sigma$ & $\mathrm{X}$ & $\mathrm{Cv}$ & Variance \\
\hline Omoologede & 0.0289 & 2.745 & 1.05 & 0.001 \\
Papa - Adeosun & 0.037 & 2.665 & 1.39 & 0.001 \\
Ishara & 0.0695 & 2.67 & 2.57 & 0.005 \\
Ago- Iwoye & 0.1026 & 2.747 & 3.73 & 0.011 \\
\hline
\end{tabular}

Table 3: Statistical Analysis for Water Absorption of Aggregates for all the Granite Sizes

\begin{tabular}{lllll}
\hline Aggregate size & $\sigma$ & $\mathrm{X}$ & $\mathrm{Cv}$ & Variance \\
\hline $9.5 \mathrm{~mm}$ & 0.0591 & 1.163 & 5.08 & 0.003 \\
$12.5 \mathrm{~mm}$ & 0.0887 & 1.11 & 7.9 & 0.008 \\
$19 \mathrm{~mm}$ & 0.1546 & 0.9025 & 17.13 & 0.024 \\
$25 \mathrm{~mm}$ & 0.0896 & 0.7467 & 11.64 & 0.008 \\
\hline
\end{tabular}

For the water absorption for the various sizes of granites, Table 3 reveals that $19 \mathrm{~mm}$ granites had the highest value of coefficient of variation of 17.13 while $9.5 \mathrm{~mm}$ had the least value of $5.08 .19 \mathrm{~mm}$ granite size had the highest value of variance of 0.024 , while $9,5 \mathrm{~mm}$ granites had the least values of 0.003 . It therefore implies that $9.5 \mathrm{~mm}$ granites with the least coefficient of variation had smaller residuals relative to the predicted value thus suggestive of a better model fit than other 
sizes while $19 \mathrm{~mm}$ with higher coefficient of variation has the greater dispersion in the variable. Both $12.5 \mathrm{~mm}$ and $25 \mathrm{~mm}$ granites have a variance of 0.008 but different values of coefficient of variations of 7.9 and 11.64 respectively. However, the analysis of results of sample based on the different quarry sites as presented in Table 4 reveals that the coefficient of variations are higher than the values obtained for the specific gravity. This implies a higher dispersion in the variables. The coefficient of variations for Ishara is the highest and that of Papa - Adeosun is the least. The same trend was observed in the value of the variance.

Although there are variations in the values of water absorption of aggregates from one site to the other, the results obtained is in line with specifications in [6], which states that aggregates should comply with either [17] or [18] and have an absorption, as measured in accordance with [19], generally not greater than $3 \%$.

\subsection{Variation in Values of Moisture Content}

Tables 5 and 6 present results of standard deviation, mean, coefficient of variation and variance of the moisture content for the various sizes and for the different quarry sites. Indications from Table 5 reveals that the value of the coefficient of variation of 63.86 for $9.5 \mathrm{~mm}$ is the highest and very high compared to other sizes. This implies much greater dispersion in the variable than all other sizes and gives an indication of poor model fit. However the coefficient of variation of other sizes are relatively low and represents a good model fit. In the case of the variance, $9.5 \mathrm{~mm}$ granites also had the highest value of 0.141 while $19 \mathrm{~mm}$ had variance. Results obtained in the analysis for the various quarry sites as presented in Table 6 also had very high coefficient of variation for samples obtained from all the quarry sites. This implies that there is very high dispersion in the variables thus representing a poor model fit.

\subsection{Variation in Mechanical Properties}

The analysis of the results obtained from the tests on the mechanical properties of granite samples obtained from the different quarry sites is presented in table 7 . The coefficient of variations for both the Aggregates Impact Value and Aggregates Crushing Values are moderately low. This is an indication of a moderate dispersion in the variables and a fairly good model fit. However the variance of the AIV is high possibly because of the higher values of the test results as well as the mean value while the values for ACV is low perhaps due to low values of the test results as well as the mean value.
Table 4: Statistical Analysis for Water Absorption of Aggregates for all the Quarry Sites

\begin{tabular}{|c|c|c|c|c|}
\hline Aggregate size & $\Sigma$ & $\mathrm{X}$ & $\mathrm{Cv}$ & Variance \\
\hline Omoologede & 0.2226 & 1.0325 & 21.56 & 0.50 \\
\hline Papa - Adeosun & 0.1504 & 1.0725 & 14.03 & 0.023 \\
\hline Ishara & 0.2439 & 0.9225 & 26.44 & 0.059 \\
\hline Ago - Iwoye & 0.1656 & 1.0633 & 15.58 & 0.027 \\
\hline
\end{tabular}

Table 5: Statistical Analysis for Moisture Content of Aggregates for all the Granite Sizes

\begin{tabular}{lllll}
\hline Aggregate size & $\Sigma$ & $\mathrm{X}$ & $\mathrm{Cv}$ & Variance \\
\hline $9.5 \mathrm{~mm}$ & 0.3757 & 1.70 & 63.86 & 0.141 \\
$12.5 \mathrm{~mm}$ & 0.1698 & 0.74 & 12.61 & 0.029 \\
$19 \mathrm{~mm}$ & 0.1915 & 0.235 & 4.5 & 0.000 \\
$25 \mathrm{~mm}$ & 0.0802 & 0.080 & 1.5 & 0.006 \\
\hline
\end{tabular}

Table 6: Statistical Analysis for Moisture Content of Aggregates for all the Quarry Sites

\begin{tabular}{lllll}
\hline Aggregate size & $\Sigma$ & $\mathrm{X}$ & $\mathrm{Cv}$ & Variance \\
\hline Omoologede & 0.4919 & 0.690 & 70.77 & 0.042 \\
Papa - Adeosun & 0.7485 & 0.733 & 102.19 & 0.560 \\
Ishara & 0.9191 & 0.793 & 115.97 & 0.845 \\
Ago - Iwoye & 0.6970 & 0.853 & 81.68 & 0.486 \\
\hline
\end{tabular}

Table 7: Statistical Analysis for Mechanical Properties of Aggregates for all the Quarry Sites.

\begin{tabular}{lllll}
\hline Mechanical properties & $\Sigma$ & $X$ & Cv & Variance \\
\hline AIV & 4.5372 & 24.37 & 18.61 & 20.586 \\
ACV & 1.4377 & 7.545 & 19.06 & 2.067 \\
\hline
\end{tabular}

Variations in the mechanical properties from the various sites notwithstanding, the results obtained are in line with recommendations in reviewed literatures. In [17] the specification for the maximum AIV for concrete is $25 \%$ which is greater than the obtained values between 18.3 and $28.12 \%$, while the ACV values of between 6.21 and $9.45 \%$ is less than recommended value of $30 \%$ [12].

\section{CONCLUSION}

It can be stated that the coefficient of variation for the Specific Gravity \& Water Absorption are low for all sizes and from all the sites while the Moisture Content is low for $25 \mathrm{~mm}, 19 \mathrm{~mm}, 12.5 \mathrm{~mm}$ and very high for $9.5 \mathrm{~mm}$ and for all sites. There is low coefficient of variation for the Aggregates Impact Values. The Aggregates Crushing Values for all sizes and from all the sites also has the same low coefficient of variation. This is in line with the 
findings of previous researchers that there are variations in the physical properties of rocks. This is expected since granites are products of rocks. The observed variations which can be attributed to geological, lithological, physical and environmental factors are in accordance with the findings of [20] and [4].

\section{REFERENCES}

[1] Vasconcelos G., Lourenço P. B., Alves C.S.A., and Pamplona J. Prediction of the Mechanical Properties of Granites by Ultrasonic Pulse Velocity and Schmidt Hammer Hardness, Tenth North American Masonry Conference June 3-5 2007 St. Louis Missouri USA.

[2] Ajitesh Anurag and Yadav R K. A Study on Variation in Mineralogical and Strength Characteristics of Some Granitic Rocks, International Journal of Engineering Research \& Technology (IJERT), Vol. 3 Issue 1, January - 2014

[3] Ramamurthy T. (2010): Engineering in Rocks for Slope, Foundations and Tunnels, Second ed., PHI Learning Pvt. Ltd., New Delhi.

[4] Ajitesh Anurag and R K Yadav, 2014, A Study on Variation In Engineering Characteristics of Some Granitic Rocks, International Journal of Engineering Research, Science \& Technology 2014, Vol. 3, No. 1, February 2014

[5] Baiyegunhi C., Oloniniyi T.L., and Gwavava O., The correlation of dry density and porosity of some rocks from the Karoo Supergroup: A case study of selected rock types between Grahamstown and Queenstown in the Eastern Cape, Province, South Africa, IOSR Journal of Engineering (IOSRJEN) Vol. 04, Issue 12 (December 2014),|V1 PP 30-40

[6] Ademeso, Odunyemi Anthony, Adekoya, John Adeyinka, Olaleye, Boluwaji Muraina, The Interrelationship of Bulk Density and Porosity of Some Crystalline Basement Complex Rocks: A Case Study of Some Rock Types In Southwestern Nigeria. IOSR Journal of Engineering Apr. 2012, Vol. 2(4) pp: 555-562

[7] Okewale, I. A, Olaleye, B. M., Correlation of Strength Properties of Limestone Deposit in Ogun State, Nigeria with Penetration Rate Using Linear Regression, Analysis for Engineering Applications,
The International Journal of Engineering and Science (IJES) Volume 2 Issue 7 Pages 18-24, 2013

[8] British Standard Institute, BS 812: Part 2, (1975). "Methods for Determination of Aggregates Impact Value", British Standard Institution London.

[9] British Standard Institute, BS 812: Part 110, (1990). "Methods for Determination of Aggregates Crushing Value", British Standard Institution London.

[10] British Standard Institute, BS 812: Part 112, (1990). "Methods for Determination of Aggregates Impact Value", British Standard Institution London.

[11] British Standard Institutes, BS EN 1097-6:2000, Tests for mechanical and physical properties of aggregates. Determination of particle density and water absorption, British Standard Institution, London.

[12] Shetty M. S. Concrete Technology Theory and Practice S. Chand \& Company Ltd. Ram Nagar, New Delhi - 110 055, 2010

[13] Nemati, K. M., Concrete Technology, Aggregates for Concrete 2015, pp 1-16,

[14] Neville A. M. Properties of Concrete, 5th edition. Pearson Education Limited 2011

[15] Arumugam, B. Effect of Specific Gravity on Aggregate Varies the Weight of Concrete Cube, International Journal of Civil Engineering (SSRG IJCR), volume 1 Issue 3, 2014, pp 1-9.

[16] British Standard Institutes, BS 8007:1987, Code of practice for the design of concrete structures for retaining aqueous liquids

[17] BS 882: 1992, "Grading or Particle Size Distribution of Fine and Coarse Aggregate" British Standard Institution London.

[18] British Standard Institutes, BS 1047:1983, Specification for air-cooled blast furnace slag aggregate for use in construction

[19] British Standard Institute, BS 812: Part 2, (1975). "Methods for Determination of Aggregates Impact Value ", British Standard Institution London.

[20] Abugudu J, Al Dwairl R.A., Hadi N.A. and Dunger B.M. Geological and Engineering Properties of Granite Rocks from Aqaba Area, South Jordan Geomaterials 6, 2016 pp $18-27$. 